Published in final edited form as:

J Am Geriatr Soc. 2018 May ; 66(5): 853-855. doi:10.1111/jgs.15290.

\title{
What are the Social Causes of Rational Suicide in Older Adults?
}

\author{
Elizabeth Dzeng, MD, PhD, MPH ${ }^{1}$ and Steven Z. Pantilat, MD ${ }^{1}$ \\ ${ }^{1}$ University of California, San Francisco (UCSF), Department of Medicine
}

In this issue of the Journal of the American Geriatrics Society, Dr. Meera Balasubramaniam discusses rational suicide in older adults, a desire for suicide in the absence of diagnosed psychiatric illness. She describes rational suicide in older adults to be of growing interest, and yet it is a topic that is rarely discussed in geriatrics ${ }^{1}$. Given the lack of psychiatric pathology associated with rational suicide, this is an issue that geriatricians are increasingly likely to encounter.

Dr. Balasubramaniam provides a compelling psychiatric analysis of the various reasons one might consider rational suicide and the interplay between the self, others, and society on this decision. In this commentary, we highlight the influence of social, economic, and political trends on rational suicide in older adults. We believe that the trends towards rational suicidal thoughts in part stems from a confluence of three factors - neoliberalism, technology, and changing attitudes related to the legalization of physician-assisted death (PAD) in some states. By spotlighting this impact of sociological trends on rational suicide, we emphasize that in order to effectively address the challenge of rational suicide, clinicians must not only address their individual patients, but also engage with societally based interventions.

Emile Durkheim, first described the sociological roots of suicide in his seminal text, Suicide $(1897)^{2}$. He found that social isolation, defined as a lack of relationships and loneliness, was an important factor that led to suicides. He used the term economic anomie to describe a subset of social causations of suicides. Economic anomie occurs when traditional institutions are no longer able to regulate key social and economic needs, thus resulting in a lack of individual belonging and a sense of disconnection from society due to weakened social cohesion. This disruption of social equilibrium occurs during periods of serious social, economic, or political upheaval, resulting in declines in economic well-being and subsequent increases in suicides.

The 1970s and 1980s saw the beginning of the neoliberal era - the political, economic, and social upheaval of our time. Neoliberal policies prioritize economic deregulation, free trade, and privatization of public goods and services ${ }^{3}$. These policies have created a culture that redefines citizens as consumers, whereby competition and market-based metrics become dominant ideological forces that permeate all aspects of human life ${ }^{4}$. Neoliberalism changed human relationships within society from a civil sphere that enshrined a commitment to social solidarity and collaboration amongst fellow citizens to that of a universal market

Corresponding Author: Elizabeth Dzeng, MD, PhD, MPH, UCSF Division of Hospital Medicine, 533 Parnassus Avenue, Box 0131, San Francisco CA 94143-0131, (410) 207-9923, liz.dzeng@ gbhi.org, Twitter: @lizdzeng. 
where human beings are fair game in calculations of profits and losses ${ }^{5}$. Rather than emancipation and freedom, the markets created atomization and loneliness ${ }^{4}$.

Neoliberal ideology in America manifests in several ways that may contribute to the increasing trend of rational suicide in older adults. One could hypothesize that thoughts of rational suicide might occur when people feel that their value to society and what they receive from society no longer feels worthwhile. In a neoliberal society that values one's utility in the market, the process of retirement and age-related declines in mental and physical capacities may have profound effects on self worth. In more traditional societies, elders had a valued and respected place in society with treasured wisdom that would be passed on to younger generations. Today, too many older adults see themselves as an appendage or even worse, a burden. In a recent New York Times article, an 82 year-old woman described "vanishing" - once she became wheelchair bound she was invisible and erased $^{6}$. Feelings of being unwanted by and invisible to society might easily slip into thoughts of erasing one's actual presence in the world.

Several authors have attributed the crisis of loneliness to neoliberalism's ideology of competitive self-interest and extreme individualism ${ }^{7,8}$. The gig economy and the widespread use of contractors in workplaces further isolates individuals who suffer from loneliness and a lack of connection by no longer having regular colleagues nor fixed work places ${ }^{9}$. This isolation is further exacerbated by the civic breakdown of "families and communities, the decline of institutions such as churches and trade unions, the switch from public transportation to private, inequality, an alienating ethic of consumerism, [and] the loss of common purpose" 8,10 . The social isolation and loneliness that ensues has contributed to an increase in mental illness and suicides in all ages ${ }^{11}$. Loneliness has profound health consequences including an increased risk of cognitive decline, dementia, depression, heart disease, and stroke ${ }^{12,13}$. Studies have demonstrated that social isolation, loneliness, and living alone increases mortality by $26-32 \% 12,14$.

Technology has often been attributed as a contributing factor towards loneliness, but its potential role in rational suicide is multi-factorial ${ }^{10}$. The technology industry has accelerated the broader temporal trends towards ageism and fear of decay that Dr. Balasubramaniam describes. Technology companies, eager to "disrupt" everything from the way we drive to the way we dry clean, have thrown down the gauntlet to "cure aging" and "solve death", as Google's Calico once declared ${ }^{15}$. More so than ever before, aging is perceived as something to be vanquished, rather than a natural human experience. The declaration of aging as a disease, pathologizes elders as an entity to be shunned and avoided, both in oneself and others ${ }^{16}$. Nick Bostrom, a philosopher and thought leader in the "radical longevity" movement states, "Aging breaks down your health and vitality, and eventually you get so weak that no amount of health care and medicine can prop you up...Just as you have begun to acquire a modicum of wisdom and experience, old age sets in to sap your energy and degrade your intellect. And then death swoops in to deliver the final insult. Now, there is real hope of ending this; that the last chapter of every human story need not play out this way"17. Given the tech elite's influence on social media, technology, and culture, these attitudes spread beyond Silicon Valley to pervade overall attitudes. 
At the same time, life-sustaining medical technologies have changed the culture of how we live with serious illness and die. It is now possible to artificially sustain multiple organs in the absence of a realistic possibility of meaningful survival of the whole person ${ }^{18}$. Concerns over overly aggressive care at the end of life and of unrelenting suffering, have in part fueled advocacy for PAD, as many people see aggressive medical interventions and unrelieved suffering at the end of life as avoidable only through premature self-inflicted death ${ }^{19}$.

The growing acceptance of PAD and its legalization in six American states and the District of Columbia plays an important role in changing attitudes towards rational suicide. An ethical concern of those opposed to PAD is the potential for the "slippery slope" whereby the legalization of PAD and the greater acceptance of PAD as a result of that legalization, initiates a trend in social perceptions towards acceptance of rational suicide, something that was previously ethically unacceptable. We believe that the legalization and more widespread acceptance of PAD was a necessary societal precursor to the rationalization of suicide in older adults. Just as PAD is increasingly accepted as a rational response to relieving suffering in the setting of terminal illness, PAD establishes a foundation for acceptance of suicide as an ethically and personally permissible response to the natural degradation of the human condition from age.

In order to mitigate the desire for rational suicide in older adults, it is important that geriatricians and primary care physicians develop awareness of this issue and understand the individual psychological and broader societal underpinnings for such a request. By understanding the individual and social etiologies of rational suicide, clinicians and the broader community will be able to advocate for medical and social support systems that might alleviate the desire for such requests.

Geriatric assessment could include loneliness and integration within one's community as a key part of the assessment. Strengthening social support systems for older adults to decrease loneliness, and ease physical and caregiving challenges is an important step in combatting impact of neoliberalism and the ensuing crisis of loneliness. Interventions could include assisting the patient in finding programs that provide community and human contact with other people. The "Campaign to End Loneliness" 20 in the United Kingdom is an example of an organization that combats loneliness in older adults through research, education, and outreach. Though technology has been implicated in increasing loneliness ${ }^{10}$, technology also has the power to connect. Helping less technologically savvy older adults to use technologies such as video chat with family members and online support groups can help alleviate loneliness.

Clinicians should also feel empowered to speak up against ageism and recognize it in themselves. Indeed, acceptance of the idea of rational suicide in older adults is in itself ageist. It implicitly endorses a view that losses associated with aging result in a life that is not worth living. The debates surrounding PAD must also recognize and consider rational suicide in older adults as a slippery slope that is already happening. The ethical and clinical challenges inherent in the discussion of rational suicide in older adults are fraught and will require further intellectual and ethical engagement of all people who care for and about elders. 


\section{Acknowledgments}

Funding source: Clinical and Translational Science Institute KL2 Program (1KL2TR001870-02) and National Palliative Care Research Center Junior Career Investigator Development Award

Conflict of Interest: The authors have no financial or personal conflicts of interest to disclose.

Author Contributions: Dr. Elizabeth Dzeng was involved in the conceptualization of ideas for this manuscript and the writing and preparation of the manuscript. Dr. Steven Pantilat was involved in the preparation of this manuscript.

Sponsor's Role: The sponsors had no role in this paper.

\section{References}

1. Balasubramaniam M. Rational Suicide in the Elderly: A Clinician's Perspective. J Am Geriatr Soc. 2018; doi: 10.1111/jgs.15263

2. Durkheim, E. Suicide: A Study in Sociology. London: Routledge Classics;

3. Chomsky, N. Profits Over People: Neoliberalism and Global Order. 1. New York, NY: Seven Stories Press; 1999.

4. Monbiot, G. How Did We Get Into This Mess?: Politics, Equality, Nature. 1. London: Verso; 2016.

5. Metcalf, S. [Accessed December 22, 2017] Neoliberalism: The Idea that Swallowed the World. The Guardian. https://www.theguardian.com/news/2017/aug/18/neoliberalism-the-idea-that-changedthe-world. Published August 18, 2017

6. Bruni, F. [Accessed December 22, 2017] Are you Old? Infirm? Then Kindly Disappear. New York Times. https://www.nytimes.com/2017/12/16/opinion/sunday/are-you-old-infirm-then-kindlydisappear.html action=click \&pgtype=Homepage $\&$ clickSource=story-heading $\&$ module=opinion-ccol-left-region\&region=opinion-c-col-left-region \&WT.nav=opinion-c-col-left-region. Published December 16, 2017

7. Monbiot, G. [Accessed December 22, 2017] Neoliberalism is creating loneliness. That's what's wrenching society apart. The Guardian. https://www.theguardian.com/commentisfree/2016/oct/12/ neoliberalism-creating-loneliness-wrenching-society-apart. Published October 12, 2016

8. Putnam, R. Bowling Alone. New York: Simon and Schuster; 2000.

9. Fisher A. There's a Loneliness Epidemic Among Freelancers. Fortune. Sep.2016

10. Monbiot, G. [Accessed December 22, 2017] The Age of Loneliness. New Statesman. Oct, 2016. https://www.newstatesman.com/politics/health/2016/10/age-loneliness

11. Curtin, SC., Warner, M., Hedegaard, H. Increase in Suicide in the United States, 1999-2014. National Center for Health Statistics, Center for Disease Control; (NCHS Data Brief No. 241)https://www.cdc.gov/nchs/products/databriefs/db241.htm. Published 2016 [Accessed December 22, 2017]

12. Holt-lunstad J, Smith TB, Baker M, Harris T, Stephenson D. Loneliness and Social Isolation as Risk Factors for Mortality: A Meta-Analytic Review. Perspect Psychol Sci. 2015; 10(2):227-237. DOI: 10.1177/1745691614568352 [PubMed: 25910392]

13. Luo Y, Hawkley LC, Waite LJ, Cacioppo JT. Loneliness, health, and mortality in old age: A national longitudinal study. Soc Sci Med. 2012; 74(6):907-914. DOI: 10.1016/j.socscimed. 2011.11.028 [PubMed: 22326307]

14. Steptoe A, Shankar A, Demakakos P, Wardle J. Social isolation, loneliness, and all-cause mortality in older men and women. PNAS. 2013; 110(15):5797-5801. DOI: 10.1073/pnas.1219686110 [PubMed: 23530191]

15. McCracken, H., Grossman, L. Google vs. Death. Time. Sep, 2013. https://content.time.com/time/ subscriber/article/0,33009,2152422,00.html

16. Khazan, O. [Accessed December 22, 2017] Should We Die?. Atl. Feb, 2017. https:// www.theatlantic.com/health/archive/2017/02/should-we-die/516357/

17. Bostrom N. The Case Against Aging. personal website. 
18. Gawande, A. Being Mortal: Medicine and What Matters in the End. 1. New York, NY: Metropolitan Books; 2014.

19. Dzeng, E. [Accessed June 7, 2016] Aid in Dying: a Triumph of Choice Over Care?. Geripal. http:// www.geripal.org/2016/06/aid-in-dying-triumph-of-choice-over-care.html. Published 2016

20. [Accessed December 28, 2017] Campaign to End Loneliness: Connections in Older Age. https:// www.campaigntoendloneliness.org/about-the-campaign/ 